HYDROBIOLOGICAL BULLETIN 20(1/2): 261 (1986)

\title{
Erratum
}

Impedance conversion as a method of research for assessing behavioural responses of aquatic invertebrates

by F. Heinis and W.R. Swain.

HYDROBIOLOGICAL BULLETIN 19(2): 183- 192 (1985)

An uncomplete version of Fig. 6 was published. The correct version is presented below.

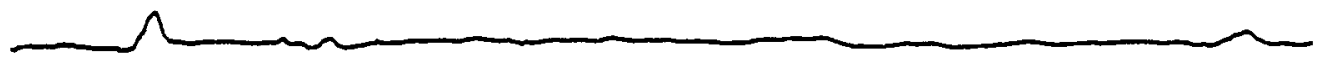

a

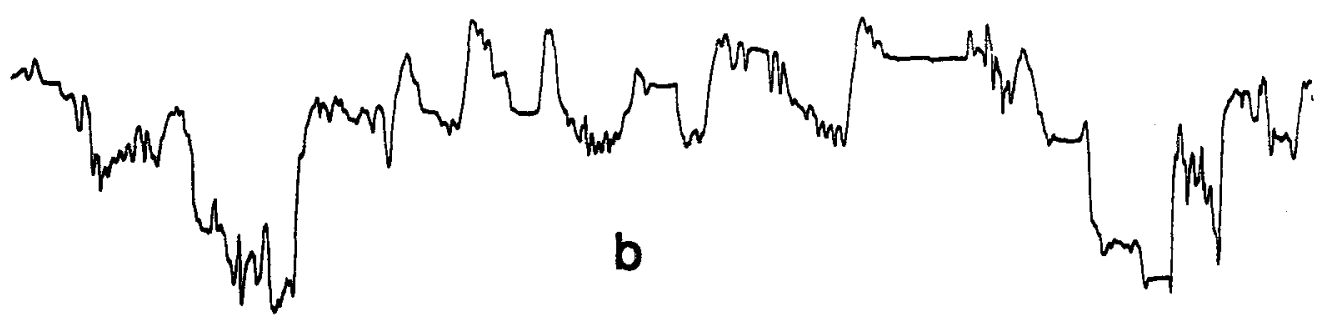

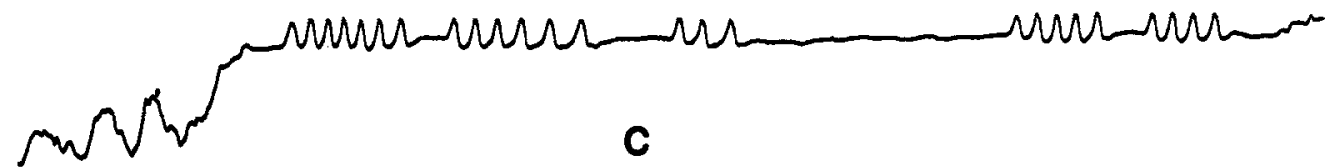

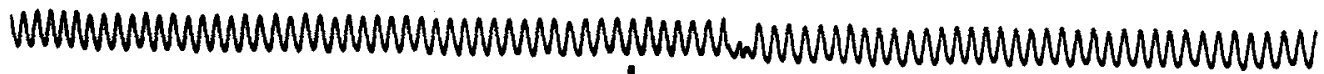 d}

\section{$30 \mathrm{sec}$}

Fig. 6. Activity signature of Chironomus sp. at various oxygen concentrations. (a) 10.4 mg. $1^{-1}$ oxygen (faint random movement pattern); (b) ca. $3.0 \mathrm{mg} . \mathrm{I}^{-1}$ oxygen (active random movement pattern); (c) $2.4 \mathrm{mg} .1^{-1}$ oxygen (intermittant ventilatory behaviour pattern, $f=0.6 \mathrm{~Hz}$ ); (d) $0.75 \mathrm{mg} .1^{-1}$ oxygen (ventilatory behaviour pattern, $f=0.9 \mathrm{~Hz}$ ). Temperature $=15^{\circ} \mathrm{C}$. 